\title{
Adherence to the World Cancer Research Fund/ American Institute for Cancer Research Guideline Is Associated With Better Health-Related Quality of Life Among Chinese Patients With Breast Cancer
}

\author{
Yuan-Yuan Lei, MD, PhD; ; Suzanne C. Ho, PhD, MPH'; Ashley Cheng, MDc; Carol Kwok, MD; \\ Chi-Kiu Iris Lee, $\mathrm{MPH}^{\mathrm{a}}$; Ka Li Cheung, BS ${ }^{\mathrm{a}}$; Roselle Lee, PhD, MPH${ }^{\mathrm{a}}$; Herbert H.F. Loong, MD, $\mathrm{PhD}^{\mathrm{a}}$; \\ Yi-Qian He, PhDa; and Winnie Yeo, MD, FRCPa
}

\begin{abstract}
Background: The 2007 World Cancer Research Fund/American Institute for Cancer Research (WCRF/AICR) guideline provides recommendations for cancer prevention among cancer survivors. Limited data have examined whether guideline adherence is related to health-related quality of life (HRQoL) among Chinese patients with breast cancer. Methods: An ongoing prospective cohort study involving 1,462 Chinese women with early-stage breast cancer assessed exercise, diet, and body mass index (BMI) at baseline and at 18-months follow-up after diagnosis. Each assessment recorded patient habits within the previous 12 months. HRQoL was evaluated by the EORTC Quality of Life Questionnaire-Core 30 (EORTC QLQ-C30). We first compared the level of adherence to WCRF/AICR recommendations before and after cancer diagnosis. We then examined whether adherence to these recommendations after diagnosis was associated with HRQoL at 18 months. Results: The mean adherence score significantly increased from baseline (3.2; SD, 1.1) to 18-month follow-up (3.9; SD, 1.1; $P<.001)$. Overall, increasing adherence to the WCRF/AICR guideline was associated with higher scores of global health status/quality of life (QoL; $\left.P_{\text {trend }}=.011\right)$, physical $\left(P_{\text {trend }}<.001\right)$ and role functioning $\left(P_{\text {trend }}=.024\right)$, and lower scores for fatigue $\left(P_{\text {trend }}=.016\right)$, nausea and vomiting $\left(P_{\text {trend }}<.001\right)$, pain $\left(P_{\text {trend }}=.004\right)$, dyspnea $\left(P_{\text {trend }}=.030\right)$, loss of appetite $\left(P_{\text {trend }}=.007\right)$, and diarrhea $\left(P_{\text {trend }}=.020\right)$. Patients with cancer who met the BMI recommendation had higher scores for physical functioning $(P=.001)$ and lower scores for fatigue $(P=.024)$, pain $(P<.001)$, and dyspnea $(P=.045)$. Adherence to physical activity recommendation was associated with better scores of global health status/QoL $(P<.001)$, physical functioning $(P=.003)$, fatigue $(P=.002)$, pain $(P=.018)$, and dyspnea $(P=.021)$. Higher adherence to diet recommendation was associated with lower scores of nausea and vomiting $\left(P_{\text {trend }}=.005\right)$, loss of appetite $\left(P_{\text {trend }}=.026\right)$, constipation $\left(P_{\text {trend }}=.040\right)$, and diarrhea $\left(P_{\text {trend }}=.031\right)$. Conclusions: Chinese patients with breast cancer made positive lifestyle changes early after cancer diagnosis. Increased adherence to WCRF/AICR recommendations after cancer diagnosis may improve HRQoL. Our data suggest that Chinese patients with breast cancer should follow the WCRF/AICR guideline to improve overall well-being.
\end{abstract}

J Natl Compr Canc Netw 2018;16(3):275-285 doi: 10.6004/jnccn.2017.7202

In Hong Kong, breast cancer is the most common malignancy and the third leading cause of cancer-related mortality among women. ${ }^{1}$ The age-standardized incidence rate was 56.7 per 100,000 people in $2011-2015$,

From the aDepartment of Clinical Oncology, Prince of Wales Hospital, the Chinese University of Hong Kong; 'Division of Epidemiology, the Jockey Club School of Public Health and Primary Care, the Chinese University of Hong Kong, New Territories; and 'Department of Clinical Oncology, Princess Margaret Hospital, Hong Kong SAR, China.

Submitted July 24, 2017; accepted for publication December 21, 2017.

The authors have disclosed that they have no financial interests,

arrangements, affiliations, or commercial interests with the manufacturers of any products discussed in this article or their competitors. and it is estimated that the number will increase to 62.5 per 100,000 people in $2021-2025 .^{2}$ On the contrary, from 1976-2010, the age-standardized mortality rate decreased on an average of $0.02 \%$ annually. ${ }^{2}$ The

This study is funded by the WCRF International (grant number WCRF 2010/249 and WCRF 2014/1197).

Author contributions: Study concept and design: Lei, Ho, Yeo. Data acquisition: Cheng, Kwok, C.K. Lee, Cheung, R. Lee, He, Loong. Manuscript preparation: Lei, Ho, Yeo. Manuscript review: Cheng, Kwok, C.K. Lee, Cheung, R. Lee, He, Loong.

Correspondence: Winnie Yeo, MD, FRCP, Department of Clinical Oncology, Prince of Wales Hospital, The Chinese University of Hong Kong, Shatin, New Territories, Hong Kong SAR, China. E-mail: winnieyeo@cuhk.edu.hk 
Lei et al

combination of increasing breast cancer incidence and improved outcomes has resulted in an expanding population of breast cancer survivors. Both the cancer diagnosis itself and the treatment-related side effects could influence patients' health-related quality of life (HRQoL). ${ }^{3-5}$ Improving HRQoL has been an important goal for the long-term management of breast cancer survivors.

There has been a considerable interest in whether lifestyle factors have an impact on HRQoL among breast cancer survivors. Epidemiologic studies have found that lifestyle factors, including maintaining normal body weight, being physically active, and eating a healthy diet, are individually associated with better HRQoL among breast cancer survivors. ${ }^{6-8}$ A cancer diagnosis has been considered as a "teachable moment," wherein survivors are likely to make lifestyle changes to promote better health outcomes. ${ }^{9}$ However, studies in the United States and Australia have revealed that few patients actually make these changes, and most patients do not adhere to the physical activity or diet recommendations. ${ }^{10-13}$ To date, limited data have compared the changes before and after diagnosis among Chinese patients with breast cancer.

In 2007, the World Cancer Research Fund/ American Institute for Cancer Research (WCRF/ AICR) issued 8 recommendations regarding diet and physical activity to reduce the risk of cancer, and encouraged cancer survivors to follow those recommendations as well. ${ }^{14}$ Several prospective cohort studies have suggested that increased adherence to the WCRF/AICR recommendations could reduce breast cancer risk. ${ }^{15-19}$ However, only a few cohort studies have explored whether higher adherence to WCRF/AICR guidelines improves HRQoL or breast cancer outcome. The Iowa Women's Health Study (IWHS) reported that increased adherence to WCRF/AICR recommendations was associated with better HRQoL and lower all-cause mortality. ${ }^{20,21}$

Our study hypothesized that patients with breast cancer would increase adherence to lifestyle recommendations after cancer diagnosis, and that adherence to a greater number of lifestyle recommendations would be associated with better HRQoL. We first compared the level of adherence to WCRF/ AICR recommendations before and after breast cancer diagnosis. We then examined whether adherence to lifestyle behavior recommendations after diagno- sis was associated with HRQoL among Chinese patients with breast cancer.

\section{Methods}

\section{Study Cohort}

The Hong Kong NTEC-KWC Breast Cancer Survival Study (HKNKBCSS) is a prospective cohort study designed to investigate the associations between phytoestrogens and other dietary and lifestyle factors and cancer recurrence and mortality. Participants were recruited from 2 regional cancer centers in Hong Kong. Eligible patients had histologically confirmed breast cancer (AJCC stage 0-III), were female, were diagnosed no more than 12 month before study entry, and did not have a prior history of breast or other cancers. The study was approved by the Joint CUHK-NTEC (the Chinese University of Hong Kong-New Territories East Cluster) Clinical Research Ethics Committee of the Chinese University of Hong Kong and the KWC Research Ethics Committee of the Hong Kong Hospital Authority.

Between January 2011 and February 2014, 2,890 Chinese patients with breast cancer were screened. Among 2,096 eligible subjects, 1,462 provided written informed consent and participated in the study (response rate, 70.0\%). Among the remaining cases, $513(24.3 \%)$ refused to participate, $18(0.8 \%)$ could not be contacted, $10(0.5 \%)$ refused treatment for breast cancer, and 93 (4.4\%) were excluded for anticipated logistical or potential compliance reasons.

According to the study protocol, the consented patients were interviewed at baseline, 18 months, 36 months, and 60 months after breast cancer diagnosis. The same questionnaire was distributed at baseline and subsequent interviews. Clinical information on disease progression and survival status was collected during follow-up. As of March 2016, the 18-month follow-up interview had been completed and included 1,310 of the 1,462 patients enrolled (follow-up rate, $89.6 \%$ ). The 36 - and 60 -month interviews have not been conducted as yet.

This study included patients who had completed the baseline and 18-month follow-up assessment. Participants who did not have their weight and height measured $(n=3)$, did not complete the questionnaire for HRQoL $(n=3)$, or reported implausible dietary intake (ie, energy intake estimates $<500$ 
or $>4,000 \mathrm{kcal} / \mathrm{d} ; \mathrm{n}=4$ ) were excluded, resulting in 1,300 patients for analysis.

\section{Data Collection}

Trained interviewers conducted face-to-face interviews. Participants were asked about their habitual dietary intake and physical activity for specific periods: the preceding 12 months before cancer diagnosis at baseline assessment, and the preceding 12 months at the 18-month follow-up assessment after cancer diagnosis.

Information on dietary intake was collected using validated and interviewer-administered food frequency questionnaires, ${ }^{22}$ which consisted of 109 food items. Participants were asked to report their usual frequency of consumption and the average amount of food intake each time. The average daily intake of nutrients and total energy were calculated according to the China Food Composition Table. ${ }^{23}$ Physical activity was measured by a validated modified Chinese Baecke Questionnaire. ${ }^{24}$ Subjects who performed sports or exercise were asked to specify the activities (up to 2 self-reported sport activities), categorically, and number of hours per week and months of the year they performed the activity. ${ }^{24}$

Hospital medical records were reviewed to obtain clinical information, including tumor histology, AJCC stage, ${ }^{25}$ estrogen receptor (ER) and progesterone receptor (PR) statuses, HER2 status, and treatment information (eg, mastectomy or breastconserving surgery, chemotherapy, radiation therapy, hormone therapy such as tamoxifen and aromatase inhibitors, and anti-HER2 therapy).

At baseline and 18-month follow-up, the selfreported total comorbidity counts included diabetes, hypertension, hyperlipidemia, chronic liver disease, and chronic kidney disease. Anthropometric measurements included body weight, height, and waist and hip circumferences, which were measured according to standard protocols.

\section{Operationalization of the WCRF/AICR Recommendations}

The WCRF/AICR has published 8 broad recommendations for cancer prevention. ${ }^{14}$ We operationalized the following 6 recommendations for constructing the adherence score: (1) body fat, ${ }^{26}$ (2) physical activity, ${ }^{27}$ (3) food and drink that promote weight gain, ${ }^{14,28}$ (4) plant-derived foods, (5) animal-source foods, and (6) alcohol. ${ }^{14}$ The recommendation on preservation, processing, and preparation of foods was not included because of insufficient data. The recommendation to meet nutritional needs through diet alone was excluded because we were unable to ascertain the reasons for supplement use, such as nutrient repletion or general health promotion. The scoring criteria are summarized in Table 1. We calculated the scores of metabolic equivalent task (MET) hours per week by multiplying the activity's corresponding MET value by the time (hours per week) engaged in the activity. ${ }^{27}$ We then summed the scores of MET hours per week of each activity to calculate the total scores. The energy density cutoff was based on a public health goal included in the WCRF/AICR recommendation that the average energy density of diets should be lower than $125 \mathrm{kcal}$ per 100 g. ${ }^{14}$ Average energy density was calculated as energy (kcal) from foods (solid foods, semisolid foods, and liquid foods such as soups) divided by the weight (gram) of those foods. ${ }^{28}$

The score assigned to each component was 1 when the recommendation was met. The third, fourth, and fifth guidelines included 2 subrecommendations, and the final component score was the average of the 2 subrecommendation scores. Scores for the 6 recommendations ( 1 for body mass index [BMI], 1 for physical activity, and 4 for dietary intake) were summed as the WCRF/AICR recommendation adherence score (range, 0-6). We further separated the adherence score into 3 components of the WCRF/AICR guideline: BMI $(0-1)$, physical activity $(0-1)$, and diet $(0-4)$. The scores for adherence to the recommendations were calculated using data collected at baseline and 18-months follow-up.

\section{HRQoL Measurement}

Quality of life (QoL) of the patients was measured using a validated Chinese version of the EORTC QoL Questionnaire-Core 30 (EORTC QLQ-C30), version 3.0. ${ }^{29}$ The QLQ-C30 was designed to assess a range of cancer-specific HRQoL issues relevant to a broad spectrum of patients with cancer. ${ }^{30}$ The QLQC30 included a global health and QoL domain, 5 functional domains (physical, role, emotional, cognitive, and social), 3 symptom domains (fatigue, nausea and vomiting, and pain) and 6 single items (dyspnea, insomnia, loss of appetite, constipation, 
Lei et al

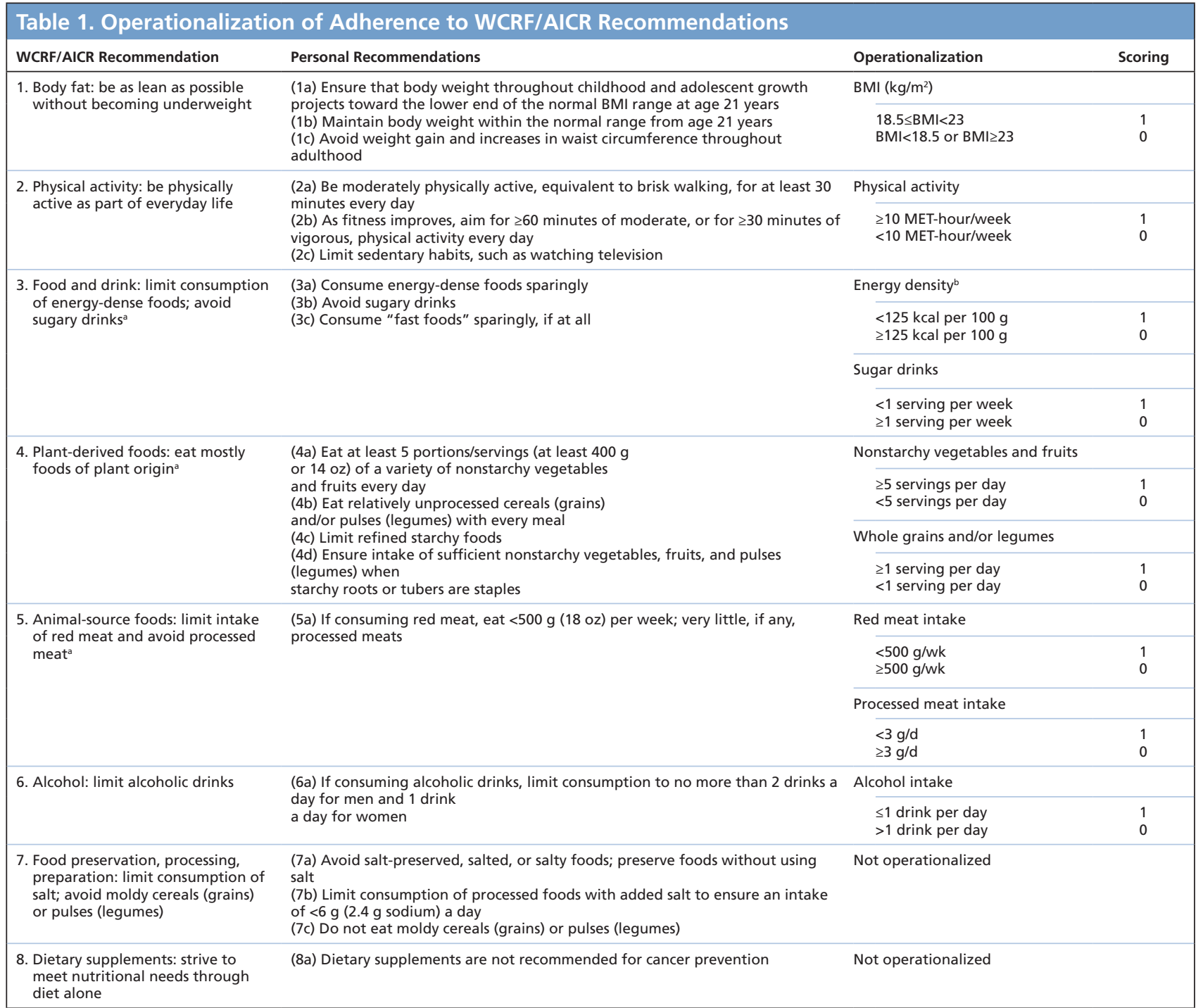

Abbreviations: BMI, body mass index; MET, metabolic equivalent task; WCRF/AICR, World Cancer Research Fund/American Institute for Cancer Research.

a The score for recommendations 3,4 , and 5 was the result of averaging the scores of each subrecommendation.

${ }^{b}$ Energy density was calculated as energy (kcal) from foods (solid foods, semisolid foods, and liquid foods such as soups) divided by the weight (gram) of those foods ( $\mathrm{kcal}$ per $100 \mathrm{~g}$ ).

diarrhea, and financial impact). Raw scores were transformed into standard scores ranging from 0 to 100. ${ }^{31}$ High scores on the global and functioning scales indicated good HRQoL, whereas high scores on the symptom scales and items represented a high level of symptoms and/or problems. ${ }^{31}$

\section{Statistical Analyses}

Paired Wilcoxon rank test was used to compare the percentage of patients with breast cancer who met each WCRF/AICR recommendation between baseline and 18-month follow-up assessment. Paired $t$-test was performed to compare the overall recommendation adherence score before and after diagno- sis. Patients were categorized into 3 groups according to the tertiles of recommendation adherence score. Characteristics of participants were compared among 3 groups through analysis of variance for continuous data and chi-square test for categorical data. To investigate the association between recommendation adherence score and HRQoL, generalized linear models were used to compare the least-square means by tertiles of adherence score (T1, T2, and T3) and continuous adherence score (eTable 1, available with this article at JNCCN.org). In the multivariate models, we adjusted for breast cancer stage at presentation, as well as age, education level, marital status, 
Guideline Adherence and Quality of Life

total number of comorbidities, smoking status, current hormonal therapy, energy intake at 18-month follow-up, and menopausal status.

Additionally, HRQoL was examined in relation to each of the 3 components of adherence score (BMI, physical activity, and diet) (supplemental eTable 2). To evaluate the association of any component with HRQoL beyond the influence from the other 2, we further adjusted the other components in each analysis. Statistical analysis was performed using $R$ software ( $R$ version 3.3.2 for Windows; $R$
Foundation for Statistical Computing, Vienna, Austria) and the differences were considered to be significant at $P<.05$.

\section{Results}

\section{Patient Characteristics}

A total of 1,300 patients with breast cancer were included. The baseline demographic and clinical characteristics are provided in Table 2 . The mean age at the time of 18 -month follow-up was 53.7 years;

\section{Table 2. Baseline Demographic and Clinical Characteristics at 18-Month Follow-Up}

\begin{tabular}{|c|c|c|c|c|c|}
\hline & \multirow[b]{2}{*}{ All } & \multicolumn{3}{|c|}{ Recommendation Adherence Score } & \multirow[b]{2}{*}{$P$ Value } \\
\hline & & $\mathrm{T} 1(\leq 3)$ & $\mathrm{T} 2(3.5-4)$ & T3 $(>4)$ & \\
\hline $\mathrm{N}$ & 1,300 & 374 & 438 & 488 & \\
\hline Recommendation adherence score, mean \pm SD & $3.9 \pm 1.1$ & $2.5 \pm 0.5$ & $3.8 \pm 0.25$ & $5.0 \pm 0.5$ & $<.001$ \\
\hline Age, mean $\pm S D, y$ & $53.7 \pm 8.9$ & $52.5 \pm 8.9$ & $54.0 \pm 9.4$ & $54.3 \pm 8.5$ & .007 \\
\hline Education level, $\%^{a}$ & & & & & .645 \\
\hline High school or below & 85.0 & 85.6 & 85.8 & 83.8 & \\
\hline College or above & 15.0 & 14.4 & 14.2 & 16.2 & \\
\hline Marital status, $\%$ & & & & & .092 \\
\hline Married or cohabitation & 70.1 & 65.8 & 71.2 & 72.3 & \\
\hline Unmarried, divorced, or widowed & 29.9 & 34.2 & 28.8 & 27.7 & \\
\hline Menopausal status, \% & & & & & .052 \\
\hline Premenopausal & 22.8 & 25.0 & 24.0 & 19.3 & \\
\hline Postmenopausal & 77.2 & 74.1 & 76.0 & 80.7 & \\
\hline Number of comorbid conditions, $\%$ & & & & & .007 \\
\hline None & 69.0 & 65.5 & 64.8 & 75.4 & \\
\hline 1 & 20.2 & 21.4 & 22.4 & 17.4 & \\
\hline 2 & 8.4 & 9.9 & 9.8 & 5.9 & \\
\hline$\geq 3$ & 2.4 & 3.2 & 3.0 & 1.2 & \\
\hline AJCC stage at diagnosis, $\%^{a}$ & & & & & .122 \\
\hline 0 & 5.6 & 7.0 & 5.7 & 4.5 & \\
\hline 1 & 30.1 & 28.6 & 27.6 & 33.4 & \\
\hline II & 45.5 & 43.6 & 45.9 & 46.5 & \\
\hline III & 18.8 & 20.9 & 20.8 & 15.6 & \\
\hline Histology ${ }^{a}$ & & & & & .313 \\
\hline IDC & 84.6 & 83.2 & 83.6 & 86.7 & \\
\hline ILC & 2.9 & 2.9 & 2.3 & 3.5 & \\
\hline DCIS & 5.6 & 7.0 & 5.7 & 4.5 & \\
\hline Other histologies & 6.8 & 7.0 & 8.4 & 5.3 & \\
\hline Estrogen receptor status, $\%^{a}$ & & & & & .936 \\
\hline Negative & 24.4 & 24.3 & 25.6 & 23.4 & \\
\hline Positive & 73.6 & 73.8 & 72.6 & 74.4 & \\
\hline Missing & 2.0 & 1.9 & 1.8 & 2.3 & \\
\hline Progesterone receptor status, $\%^{a}$ & & & & & .980 \\
\hline Negative & 40.9 & 39.8 & 41.6 & 41.2 & \\
\hline Positive & 56.8 & 57.8 & 56.4 & 56.4 & \\
\hline Missing & 2.3 & 2.4 & 2.1 & 2.5 & \\
\hline HER2 status, $\%^{a}$ & & & & & .615 \\
\hline Negative & 67.0 & 69.3 & 66.4 & 65.8 & \\
\hline Positive & 26.5 & 24.3 & 25.8 & 28.9 & \\
\hline Missing & 6.5 & 6.4 & 7.7 & 5.3 & \\
\hline \multicolumn{6}{|l|}{ Treatment, \% } \\
\hline Surgery & 99.9 & 100 & 99.9 & 100 & .374 \\
\hline Chemotherapy & 76.5 & 77.5 & 76.7 & 75.6 & .799 \\
\hline Radiation therapy & 71.5 & 72.5 & 74.4 & 68.0 & .087 \\
\hline Hormone therapy & 74.1 & 73.3 & 74.2 & 74.6 & .905 \\
\hline Energy intake, mean $\pm \mathrm{SD}, \mathrm{kcal} / \mathrm{d}$ & $1,361.2 \pm 386.8$ & $1,492.9 \pm 428.7$ & $1,327.2 \pm 377.9$ & $1,338.9 \pm 353.6$ & $<.001$ \\
\hline Current smoking, $\%$ & 1.2 & 2.7 & 0.7 & 0.4 & .005 \\
\hline
\end{tabular}

Current smoking, \%

1.2

2.7

0.7

0.4

.005

Research Fund/American Institute for Cancer Research.

${ }^{a}$ Data collected at baseline survey, other data collected at 18-month follow-up survey. 
Lei et al

64.3\% had AJCC stage II and III breast cancer. The proportion of tumors with ER, PR, and HER2 positivity was $73.6 \%, 56.8 \%$, and $26.5 \%$, respectively. At 18-month follow-up, $74.1 \%$ of the participants were undergoing adjuvant endocrine therapy.

\section{Adherence to WCRF/AICR Recommendations Before and After Diagnosis}

Table 3 shows the proportion of participants who met each recommendation or subrecommendation at baseline and at 18-month follow-up. The proportion of patients who had normal BMI (18.5-22.9 $\mathrm{kg} / \mathrm{m}^{2}$ ) before and after cancer diagnosis was almost the same, at approximately $45 \%$; 68 patients (5.2\%) had BMI $<18.5 \mathrm{~kg} / \mathrm{m}^{2}$, and only 7 patients had comorbidities. The proportion of women who met the WCRF/AICR recommendations for physical activity ( $\geq 10$ MET-hours/week) was very low: only $21.4 \%$ met the criteria at prediagnosis, increasing to $33.8 \%$ postdiagnosis. However, the proportion of patients who met the recommendations regarding alcohol was very high at both assessments: $98.5 \%$ at baseline and $100 \%$ at 18 -month follow-up. For other dietary components, the proportions of patients who met the recommendation were all increased after diagnosis, ranging from $37.5 \%$ to $67.2 \%$ at baseline to $40.2 \%$ to $85.4 \%$ at 18 -month follow-up.

Paired Wilcoxon rank test showed that, except for recommendations regarding BMI and intake of whole grain and/or legumes, the proportion of patients who met the other recommendations or subrecommendations significantly increased at 18-month follow-up (all $\mathrm{P}<.001$; Table 3). Before cancer diagnosis, the mean recommendation adherence score was $3.2(\mathrm{SD}, 1.1)$ in the whole cohort, and $64.2 \%$ of the patients had a higher adherence score after diagnosis. At 18-month follow-up, the mean recommendation adherence score significantly increased to 3.9 (SD, $1.1 ; P<.001)$.

We compared patient characteristics by the tertiles of adherence score (T1, T2, and T3) at 18-month follow-up. Patients who received higher adherence scores were older, had fewer comorbidities, had less energy intake ( $\mathrm{kcal} / \mathrm{d})$, and showed lower prevalence of current smoking (Table 2).

\section{Association of Recommendation Adherence Score With HRQoL at Follow-Up}

The score for HRQoL items ranged from 0 to 100 , and a high score for the global health status/QoL or functional domains represented a high $\mathrm{QoL}$ or high level of functioning. Increasing adherence to the recommendations (as evaluated by tertile) was associated with significantly higher global health and QoL score (Table 4; 64.25 vs 65.28 vs 67.34, respectively; $\left.P_{\text {trend }}=.011\right)$. The global health and QoL score increased by 1.47 points with every 1 -point increment in adherence score. For functional domains, higher adherence to the recommendations had significantly higher scores of physical functioning ( 89.00 vs 90.30 vs 92.18 , respectively; $P_{\text {trend }}<.001$ ) and role functioning (93.58 vs 93.79 vs 95.78 respec-

\begin{tabular}{|c|c|c|c|c|c|}
\hline $\begin{array}{l}\text { Operationalization of WCRF/AICR } \\
\text { Recommendations }\end{array}$ & Meet or Not Meet & Scoring & $\begin{array}{l}\mathrm{N}(\%), \\
\text { at Baseline }\end{array}$ & $\begin{array}{c}\mathrm{N}(\%), \\
\text { at 18-Month Follow-Up }\end{array}$ & $P$ Value \\
\hline 1. $\mathrm{BMI}\left(\mathrm{kg} / \mathrm{m}^{2}\right)$ & $\begin{array}{l}18.5 \leq \mathrm{BMI}<23 \\
\mathrm{BMI}<18.5 \text { or } \mathrm{BMI} \geq 23\end{array}$ & $\begin{array}{l}1 \\
0\end{array}$ & $\begin{array}{l}572(44.0) \\
728(56.0)\end{array}$ & $\begin{array}{l}595(45.8) \\
705(54.2)\end{array}$ & .135 \\
\hline 2. Physical activity & $\begin{array}{l}\geq 10 \mathrm{MET} \text {-hour/wk } \\
<10 \mathrm{MET}-\text { hour/wk }\end{array}$ & $\begin{array}{l}1 \\
0\end{array}$ & $\begin{array}{r}278(21.4) \\
1,022(78.6)\end{array}$ & $\begin{array}{l}439(33.8) \\
861(66.2)\end{array}$ & $<.001$ \\
\hline 3.1 Energy density & $\begin{array}{l}<125 \mathrm{kcal} \text { per } 100 \mathrm{~g} \\
\geq 125 \mathrm{kcal} \text { per } 100 \mathrm{~g}\end{array}$ & $\begin{array}{l}1 \\
0\end{array}$ & $\begin{array}{l}762(58.6) \\
538(41.4)\end{array}$ & $\begin{array}{r}1,094(85.4) \\
206(15.8)\end{array}$ & $<.001$ \\
\hline 3.2 Sugar drinks ${ }^{b}$ & $\begin{array}{l}<1 \text { serving per week } \\
\geq 1 \text { serving per week }\end{array}$ & $\begin{array}{l}1 \\
0\end{array}$ & $\begin{array}{l}874(67.2) \\
426(32.8)\end{array}$ & $\begin{array}{r}1,110(85.4) \\
190(14.6)\end{array}$ & $<.001$ \\
\hline 4.1 Nonstarchy vegetables and fruits ${ }^{b}$ & $\begin{array}{l}\geq 5 \text { servings per day } \\
<5 \text { servings per day }\end{array}$ & $\begin{array}{l}1 \\
0\end{array}$ & $\begin{array}{l}698(53.7) \\
602(46.3)\end{array}$ & $\begin{array}{l}857(65.9) \\
443(34.1)\end{array}$ & $<.001$ \\
\hline 4.2 Whole grains and/or legumes ${ }^{b}$ & $\begin{array}{l}\geq 1 \text { serving per day } \\
<1 \text { serving per day }\end{array}$ & $\begin{array}{l}1 \\
0\end{array}$ & $\begin{array}{l}488(37.5) \\
812(62.5)\end{array}$ & $\begin{array}{l}523(40.2) \\
777(59.8)\end{array}$ & .093 \\
\hline 5.1 Red meat intake ${ }^{\mathrm{b}}$ & $\begin{array}{l}<500 \mathrm{~g} / \mathrm{wk} \\
\geq 500 \mathrm{~g} / \mathrm{wk}\end{array}$ & $\begin{array}{l}1 \\
0\end{array}$ & $\begin{array}{l}599(46.1) \\
701(53.9)\end{array}$ & $\begin{array}{l}867(66.7) \\
433(33.3)\end{array}$ & $<.001$ \\
\hline 5.2 Processed meat intake ${ }^{b}$ & $\begin{array}{l}<3 \mathrm{~g} / \mathrm{d} \\
\geq 3 \mathrm{~g} / \mathrm{d}\end{array}$ & $\begin{array}{l}1 \\
0\end{array}$ & $\begin{array}{l}651(50.1) \\
649(49.9)\end{array}$ & $\begin{array}{l}945(72.7) \\
355(27.3)\end{array}$ & $<.001$ \\
\hline 6. Alcohol intake ${ }^{b}$ & $\begin{array}{l}\leq 1 \text { drink per day } \\
>1 \text { drink per day }\end{array}$ & $\begin{array}{l}1 \\
0\end{array}$ & $\begin{array}{c}1,280(98.5) \\
20(1.5)\end{array}$ & $\begin{array}{c}1,300(100) \\
0(0)\end{array}$ & $<.001$ \\
\hline
\end{tabular}

Abbreviations: BMI, body mass index; MET, metabolic equivalent task; WCRF/AICR, World Cancer Research Fund/American Institute for Cancer Research. aEnergy density was calculated as energy (kcal) from foods (solid foods, semi-solid foods, and liquid foods such as soups) divided by the weight (gram) of those foods (kcal per $100 \mathrm{~g}$ ).

${ }^{6}$ The score for recommendations 3,4 , and 5 was the result of averaging the scores of each subrecommendation. 
Guideline Adherence and Quality of Life

\begin{tabular}{|c|c|c|c|c|c|c|c|c|c|c|}
\hline & \multicolumn{10}{|c|}{ WCRF/AICR Adherence Score } \\
\hline & \multicolumn{2}{|c|}{$\mathrm{T} 1(\leq 3 ; \mathrm{n}=374)$} & \multicolumn{2}{|c|}{ T2 (3.5-4; n=438) } & \multicolumn{2}{|c|}{ T3 $(>4 ; n=488)$} & \multirow[b]{2}{*}{$P_{\text {trend }}$} & \multicolumn{3}{|c|}{ Continuous $^{a}$} \\
\hline & LS Means & SE & LS Means & SE & LS Means & SE & & LS Means & SE & $P$ Value \\
\hline \multicolumn{11}{|l|}{ EORTC QLQ-C30 } \\
\hline Global health status/QoL & 64.25 & 0.92 & 65.58 & 0.84 & 67.34 & 0.8 & .011 & 1.47 & 0.46 & .001 \\
\hline \multicolumn{11}{|l|}{ Functioning } \\
\hline Physical & 89.00 & 0.59 & 90.30 & 0.54 & 92.18 & 0.52 & $<.001$ & 1.39 & 0.29 & $<.001$ \\
\hline Role & 93.58 & 0.75 & 93.79 & 0.69 & 95.78 & 0.66 & .024 & 1.24 & 0.38 & $<.001$ \\
\hline Emotional & 84.11 & 0.97 & 85.70 & 0.89 & 85.53 & 0.85 & .300 & 0.43 & 0.48 & .371 \\
\hline Cognitive & 81.16 & 0.99 & 79.53 & 0.90 & 80.02 & 0.86 & .429 & -0.05 & 0.49 & .906 \\
\hline Social & 93.58 & 0.81 & 93.73 & 0.74 & 92.92 & 0.70 & .512 & 0.16 & 0.40 & .698 \\
\hline \multicolumn{11}{|l|}{ Symptom/Problem } \\
\hline Fatigue & 21.44 & 1.02 & 19.45 & 0.94 & 18.11 & 0.89 & .016 & -1.62 & 0.51 & .002 \\
\hline Nausea and vomiting & 2.47 & 0.33 & 2.00 & 0.30 & 0.96 & 0.29 & $<.001$ & -0.48 & 0.17 & .003 \\
\hline Pain & 21.85 & 1.19 & 19.39 & 1.09 & 17.29 & 1.04 & .004 & -2.19 & 0.59 & $<.001$ \\
\hline Dyspnea & 10.03 & 0.88 & 8.55 & 0.81 & 7.45 & 0.77 & .030 & -1.20 & 0.44 & .007 \\
\hline Insomnia & 23.52 & 1.49 & 23.05 & 1.37 & 22.49 & 1.30 & .604 & -0.48 & 0.74 & .520 \\
\hline Loss of appetite & 6.25 & 0.70 & 3.94 & 0.64 & 3.62 & 0.61 & .007 & -1.12 & 0.35 & .001 \\
\hline Constipation & 10.25 & 1.04 & 8.96 & 0.95 & 8.63 & 0.91 & .254 & -0.75 & 0.52 & .148 \\
\hline Diarrhea & 5.14 & 0.64 & 4.06 & 0.59 & 3.14 & 0.56 & .020 & -1.07 & 0.32 & $<.001$ \\
\hline Financial impact & 10.60 & 1.21 & 10.89 & 1.11 & 13.32 & 1.05 & .081 & 0.82 & 0.60 & .176 \\
\hline
\end{tabular}

Models were adjusted for age at 18-month follow-up (years, continuous), education level at baseline (high school or below, college or above), marital status at 18-month follow-up (married or cohabitation, unmarried or divorced or widowed), total number of comorbidities at 18-month follow-up (0, 1, 2, 3), smoking status at 18-month follow-up (yes/no), stage at diagnosis (0, I, II, III), current hormonal therapy use at 18-month follow-up (yes/no), energy intake at 18-month follow-up (kcal per day, continuous), and menopausal status (premenopause, postmenopause).

Abbreviations: EORTC QLQ-C30, European Organization for Research and Treatment of Cancer Quality of Life Questionnaire-Core 30; HRQoL, health-related quality of life;

LS, least-square; SE, standard error; T, tertile of adherence score; WCRF/AICR, World Cancer Research Fund/American Institute for Cancer Research.

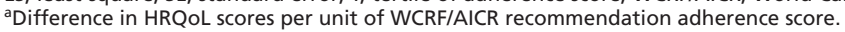

tively; $\left.P_{\text {trend }}=.024\right)$. The physical functioning score increased 1.39 points and role functioning score increased 1.24 points with each 1 -point increment in adherence scores. For symptom evaluation, patients who had higher adherence to recommendations had significantly lower scores of symptoms (representing low level of symptoms), including fatigue (21.44 vs 19.45 vs 18.11 , respectively; $P_{\text {trend }}=.016$ ), nausea and vomiting (2.47 vs 2.00 vs 0.96 , respectively; $\left.P_{\text {trend }}<.001\right)$, pain (21.85 vs 19.39 vs 17.29 , respectively; $\left.P_{\text {trend }}=.004\right)$, dyspnea (10.03 vs 8.55 vs 7.45 , respectively; $\left.P_{\text {trend }}=.030\right)$, loss of appetite $(6.25$ vs 3.94 vs 3.62, respectively; $\left.P_{\text {trend }}=.007\right)$, and diarrhea ( 5.14 vs 4.06 vs 3.14 , respectively; $\left.P_{\text {trend }}=.020\right)$. With each 1 -point increment in adherence scores, the score of the above symptoms decreased accordingly: fatigue $(-1.62$ points), nausea and vomiting $(-0.48$ points), pain ( -2.19 points), dyspnea ( -1.20 points), loss of appetite $(-1.12$ points), and diarrhea $(-1.07$ points).

\section{Association of Individual Recommendation Component Score at Follow-Up With HRQoL}

We also examined the associations between HRQoL and 3 recommendation components (BMI, physical activity, and diet). After adjusting for clinical and demographic factors, physical activity level, and adherence to dietary recommendations, patients with cancer who were within the normal BMI range had higher scores for physical functioning (Table 5; $P=.001)$ and lower scores for fatigue $(P=.024)$, pain $(P<.001)$, and dyspnea $(P=.045)$.

To evaluate the relationship between physical activity level and HRQoL, we included clinical and demographic factors, BMI, and adherence to dietary recommendations in the adjustment. Patients who adhered to the physical activity recommendations had significantly higher scores for global health status and $\mathrm{QoL}(P<.001)$ and physical functioning $(P=.003)$, and lower scores for fatigue $(P=.002)$, pain $(P=.018)$, and dyspnea $(P=.021)$ compared with patients who were nonadherent.

For analysis regarding diet, patients were categorized into 3 groups by the tertiles of dietary recommendations adherence score at 18-month follow-up. Apart from clinical and demographic factors, BMI and physical activity scores were also adjusted in this analysis. Those who had higher scores for dietary recommendations showed lower scores for symptoms, including nausea and vomiting $\left(P_{\text {trend }}=.005\right)$, loss of 
Lei et al

\begin{tabular}{|c|c|c|c|c|c|c|c|c|c|c|}
\hline \multirow[b]{2}{*}{ HRQoL Items } & \multicolumn{3}{|c|}{ BMI Score } & \multicolumn{3}{|c|}{ Physical Activity Score } & \multicolumn{3}{|c|}{ Dietary Adherence Score } & \multirow[b]{2}{*}{$P_{\text {trend }}$} \\
\hline & $0(n=705)$ & $1(n=595)$ & $P$ Value $^{\mathrm{a}}$ & $0(n=861)$ & $1(n=439)$ & $P$ Value $^{\mathrm{b}}$ & $\begin{array}{c}\mathrm{T} 1 \\
(\leq 2.5 ; n=373)\end{array}$ & $\begin{array}{c}\mathrm{T} 2 \\
(3 ; n=323)\end{array}$ & $\begin{array}{c}\mathrm{T3} \\
(\geq 3.5 ; \mathrm{n}=604)\end{array}$ & \\
\hline \multicolumn{11}{|l|}{$\begin{array}{l}\text { EORTC QLQ-C30, } \\
\text { LS means (SE) }\end{array}$} \\
\hline $\begin{array}{l}\text { Global health } \\
\text { status/QoL }\end{array}$ & $65.47(0.67)$ & $66.32(0.73)$ & .395 & $64.48(0.60)$ & $68.56(0.85)$ & $<.001$ & $65.12(0.94)$ & $65.89(0.97)$ & $66.30(0.72)$ & .340 \\
\hline \multicolumn{11}{|l|}{ Functioning } \\
\hline Physical & $89.69(0.43)$ & $91.75(0.47)$ & .001 & $89.95(0.39)$ & $91.96(0.55)$ & .003 & $90.18(0.61)$ & $90.33(0.63)$ & $91.07(0.47)$ & .228 \\
\hline Role & $94.13(0.55)$ & $94.88(0.60)$ & .359 & $93.95(0.50)$ & $95.50(0.70)$ & . 077 & $93.00(0.78)$ & $95.37(0.80)$ & $94.91(0.60)$ & .089 \\
\hline Emotional & $85.67(0.70)$ & $84.60(0.77)$ & .313 & $84.70(0.64)$ & $86.12(0.91)$ & .210 & $85.10(1.00)$ & $84.10(1.03)$ & $85.80(0.77)$ & .476 \\
\hline Cognitive & $79.96(0.72)$ & $80.44(0.78)$ & .661 & $79.76(0.65)$ & $81.01(0.92)$ & .275 & $81.46(1.02)$ & $80.63(1.05)$ & $79.15(0.78)$ & .069 \\
\hline Social & $92.89(0.59)$ & $93.97(0.64)$ & .224 & $93.38(0.53)$ & $93.39(0.75)$ & .987 & $93.81(0.83)$ & $93.54(0.86)$ & $93.04(0.64)$ & .461 \\
\hline \multicolumn{11}{|l|}{ Symptom/Problem } \\
\hline Fatigue & $20.68(0.74)$ & $18.15(0.81)$ & .024 & $20.78(0.67)$ & $17.05(0.95)$ & .002 & $19.77(1.05)$ & $19.03(1.09)$ & $19.63(0.81)$ & .981 \\
\hline $\begin{array}{l}\text { Nausea and } \\
\text { vomiting }\end{array}$ & $1.99(0.24)$ & $1.45(0.26)$ & .135 & $1.75(0.22)$ & $1.73(0.31)$ & .942 & $2.32(0.34)$ & $2.16(0.35)$ & $1.17(0.26)$ & .005 \\
\hline Pain & $21.37(0.86)$ & $16.86(0.94)$ & $<.001$ & $20.42(0.78)$ & $17.13(1.11)$ & .018 & $19.64(1.22)$ & $19.30(1.26)$ & $19.10(0.94)$ & .737 \\
\hline Dyspnea & $9.45(0.64)$ & $7.52(0.70)$ & .045 & $9.36(0.58)$ & $7.01(0.81)$ & .021 & $8.51(0.91)$ & $8.76(0.94)$ & $8.49(0.70)$ & .964 \\
\hline Insomnia & $22.74(1.09)$ & $23.26(1.19)$ & .750 & $23.36(0.98)$ & $22.26(1.39)$ & .514 & $24.13(1.54)$ & $22.23(1.59)$ & $22.66(1.18)$ & .511 \\
\hline Loss of appetite & $4.93(0.51)$ & $3.96(0.56)$ & .210 & $4.73(0.46)$ & $4.02(0.66)$ & .389 & $5.95(0.72)$ & $4.14(0.75)$ & $3.77(0.56)$ & .026 \\
\hline Constipation & $8.78(0.75)$ & $9.71(0.82)$ & .408 & $9.43(0.68)$ & $8.76(0.97)$ & .574 & $10.93(1.07)$ & $9.29(1.10)$ & $8.09(0.82)$ & .040 \\
\hline Diarrhea & $4.44(0.46)$ & $3.53(0.51)$ & .191 & $4.29(0.42)$ & $3.52(0.60)$ & .299 & $5.45(0.66)$ & $3.42(0.68)$ & $3.47(0.51)$ & .031 \\
\hline Financial impact & $11.87(0.88)$ & $11.54(0.96)$ & .800 & $11.87(0.80)$ & $11.42(1.13)$ & .752 & $10.04(1.25)$ & $11.32(1.29)$ & $12.97(0.96)$ & .064 \\
\hline
\end{tabular}

Covariants included age at 18-month follow-up (years, continuous), education level at baseline (high school or below, college or above), marital status (married or cohabitation, unmarried or divorced or widowed), total number of comorbidities at 18-month follow-up $(0,1,2,3)$, smoking status at 18-month follow-up (yes/no), stage at diagnosis (0, I, II, III), current hormonal therapy use at 18-month follow-up (yes/no), energy intake at 18-month follow-up (kcal per day, continuous), and menopausal status

(premenopause, postmenopause). Abbreviations: BMI, body mass index; EORTC QLQ-C30, European Organization for Research and Treatment of Cancer Quality of Life Questionnaire-Core 30; HRQoL, health-
related quality of life; LS, least-square; SE, standard error; QoL, quality of life; T, tertile of adherence score; WCRF/AICR, World Cancer Research Fund/American Institute for Cancer Research.

${ }^{2}$ Adjust for covariants, physical activity score, and dietary adherence score.

${ }^{b}$ Adjust for covariants, BMI score, and dietary adherence score.

'Adjust for covariants, BMI score, and physical activity score.

appetite $\left(P_{\text {trend }}=.026\right)$, constipation $\left(P_{\text {trend }}=.040\right)$, and diarrhea $\left(P_{\text {trend }}=.031\right)$.

\section{Discussion}

This is the first study to measure adherence to the WCRF/AICR guidelines before and after cancer diagnosis among Chinese patients with breast cancer. Our results indicated that patients tended to make positive changes for a healthier lifestyle after cancer diagnosis. We also examined the association between adherence to WCRF/AICR guidelines after cancer diagnosis and HRQoL, and found that higher adherence to WCRF/AICR recommendations after cancer diagnosis was associated with higher scores of global health status/QoL, physical and role functioning, and a series of improved symptoms. Among the 3 components of the WCRF/AICR guideline (BMI, physical activity, and diet), we found that adherence to the physical activity recommendations was associated with better global health status and QoL, better physical functioning, and lower scores for fatigue, pain, and dyspnea. Adherence to the BMI recom- mendation also resulted in better physical functioning and lower scores for fatigue, pain, and dyspnea. Adherence to dietary recommendations was associated with lower scores for nausea and vomiting, loss of appetite, constipation, and diarrhea. Further, the significant associations between adherence to WCRF/AICR guidelines and HRQoL were also seen in sensitivity analysis (data not shown).

Many studies have shown that patients with breast cancer attempt to modify their lifestyles after cancer diagnosis. ${ }^{32-37}$ Behavioral changes typically included increased intake of fruit and vegetables, decreased meat intake, reduced smoking and alcohol consumption, and increased physical activity. ${ }^{32-37}$ Findings of those studies indicated that patients are willing and able to initiate positive changes. Our results further demonstrated that Chinese patients with breast cancer made significant changes in dietary intake and physical activity early after diagnosis, and suggested that "early after diagnosis" was an important period for patients to adopt healthy lifestyle habits. However, it may be possible that the patients willing to participate in this cohort were those 
who cared more about lifestyle behaviors, and therefore were more likely to change their lifestyles than the general breast cancer population.

Our finding of the association between higher adherence to WCRF/AICR guidelines and better HRQoL was consistent with the results of 2 previous studies. ${ }^{12,20}$ The American Cancer Society's (ACS) Study of Cancer Survivors-II examined the association between adherence to ACS recommendations for lifestyle behavior (physical activity, fruit and vegetable consumption, and smoking) and HRQoL among 6 groups of cancer survivors. Results indicated that patients who adhered to a greater number of recommendations had better overall HRQoL. ${ }^{12}$ The IWHS reported that elderly female cancer survivors (age $\geq 65$ years) who adhered to an increasing number of WCRF/AICR recommendations had higher physical and mental summary scores. ${ }^{20}$ However, these studies mainly included long-term cancer survivors, with approximately two-thirds of the participants diagnosed $>5$ years prior to the study. On the other hand, a Korean cross-sectional study that assessed 160 patients who were between 6 months and $>5$ years from initial breast cancer diagnosis found that higher adherence to ACS recommendations was associated with better social functioning, whereas higher adherence to WCRF/AICR recommendations was associated with more serious arm symptoms (pain in arm or shoulder, arm or hand swollen and difficult to raise or move arm sideways). ${ }^{38}$ In contrast, the present study assessed patients relatively early, with a median follow-up time from cancer diagnosis of 18 months. At the time of writing, patients just finished intense anticancer therapy, such as surgery, radiotherapy, and/or chemotherapy, which is a critical period for adopting lifestyle changes. This is supported by similar cohort studies that also assessed updates in lifestyle factors at 18 months after cancer diagnosis, including the Shanghai Breast Cancer Survival Study ${ }^{39}$ and the DietCompLyf study. ${ }^{40}$

Our study is the first to investigate the association between BMI and HRQoL among Chinese patients with breast cancer. We found that patients who adhered to the BMI recommendation had better physical functioning. Such association was in line with the results of previous studies, which demonstrated that greater BMI $\left(\geq 25 \mathrm{~kg} / \mathrm{m}^{2}\right)$ was associated with poorer physical QoL. ${ }^{13,41,42}$ A systematic review of randomized trials among patients after primary treatment for breast cancer suggested that physical activity has positive effects on physical functions and QoL. ${ }^{43}$ Physical activity has been suggested to improve physical function through improving cardiovascular function. ${ }^{44}$ Another meta-analysis that included 25 exercise intervention trials concluded that exercise interventions significantly improved overall QoL in breast cancer survivors. ${ }^{45}$ Additionally, a systematic review found that aerobic exercise during or after adjuvant cancer therapy could significantly reduce fatigue in patients with breast cancer. ${ }^{46}$ Together, this evidence supported our finding that patients with breast cancer who had been physically active showed better scores for global health status/ QoL, physical functioning, and fatigue. Furthermore, a few intervention studies have shown that dietary modifications in addition to exercise interventions could induce weight loss and improve $\mathrm{QoL}$ in patients with breast cancer. ${ }^{47-50}$

This study measured both prediagnosis and postdiagnosis lifestyle behaviors to examine changes across a specific period. Additionally, we comprehensively recorded the demographic and clinical characteristics of our participants and adjusted those potential confounders during the analysis. Despite the study's strength, some limitations must be considered. First, our finding may not be generalized to all Chinese patients with breast cancer. Because Hong Kong is a relatively more Westernized and urbanized city in China, its population may have different lifestyle behaviors compared with populations in different localities. Second, the median followup time from diagnosis was relatively short. It will be important to prospectively follow these participants and determine if adherence perseveres. InoueChoi et $\mathrm{al}^{21}$ reported that higher adherence to the WCRF/AICR guidelines was associated with lower all-cause mortality among elderly female cancer survivors (aged $\geq 65$ years). Prospective follow-up of the current cohort may allow us to determine whether this association exists among Chinese breast cancer survivors.

Third, although patients with breast cancer at 18-month follow-up had completed surgery, radiotherapy, and/or chemotherapy, the possible longterm influence of these treatments and the ongoing influence of endocrine therapy on HRQoL have not been assessed. Fourth, we acknowledge the potential recall bias of the impact of a breast cancer diagnosis 
Lei et al

on patients' report of recent lifestyle and behavior changes. A better design may be to include appropriate comparison groups for investigating the impact of breast cancer diagnosis on a change in behavior. In addition, because the study design about the association between adherence to WCRF/AICR recommendation and HRQoL was similar to the study by Inoue-Choi et al, ${ }^{20}$ potential bias similar to the latter study should be considered.

Lastly, our scoring methods to estimate the overall adherence to WCRF/AICR recommendations were based on a set of cutoff values adopted for this study, and this could have introduced potential differences in results compared with other studies using different scoring systems. For instance, although the IWHS used daily dietary fiber intake to construct the adherence score,${ }^{20}$ the crosssectional study from South Korea used the tertiles of the whole population to construct the adherence score. ${ }^{38}$

\section{Conclusions}

Results of our study showed that Chinese patients with breast cancer made positive lifestyle changes after their cancer diagnosis and increased their adherence to WCRF/AICR guidelines. Moreover, higher adherence to WCRF/AICR recommendations among Chinese patients was associated with better global health status/QoL and physical and role functioning, and less serious symptoms. Our results provide evidence of the beneficial outcomes for patients with breast cancer adhering to the WCRF/AICR prevention guideline. Prospective follow-up data could confirm whether adherence to WCRF/AICR recommendations remains a long-term practice and whether this has an impact on cancer mortality.

\section{References}

1. Overview of Hong Kong Cancer Statistics of 2014. Available at: http:// www3.ha.org.hk/cancereg/pdf/overview/Summary\%20of $\% 20$ CanStat $\% 20$ 2014.pdf. Accessed April 1, 2017

2. Wong IO, Schooling CM, Cowling BJ, et al. Breast cancer incidence and mortality in a transitioning Chinese population: current and future trends. Br J Cancer 2015;112:167-170.

3. Lu W, Cui Y, Zheng Y, et al. Impact of newly diagnosed breast cancer on quality of life among Chinese women. Breast Cancer Res Treat 2007;102:201-210.

4. Taghian NR, Miller CL, Jammallo LS, et al. Lymphedema following breast cancer treatment and impact on quality of life: a review. Crit Rev Oncol Hematol 2014;92:227-234

5. Hwang SY, Chang SJ, Park BW. Does chemotherapy really affect the quality of life of women with breast cancer? J Breast Cancer 2013;16:229 235.

6. Imayama I, Alfano CM, Neuhouser ML, et al. Weight, inflammation, cancer-related symptoms and health related quality of life among breast cancer survivors. Breast Cancer Res Treat 2013;140:159-176.

7. Chen $X$, Zheng $Y$, Zheng W, et al. The effect of regular exercise on quality of life among breast cancer survivors. Am J Epidemiol 2009;170:854-862.

8. Wayne SJ, Baumgartner K, Baumgartner RN, et al. Diet quality is directly associated with quality of life in breast cancer survivors. Breast Cancer Res Treat 2006;96:227-232.

9. Demark-Wahnefried W, Aziz NM, Rowland JH, et al. Riding the crest of the teachable moment: promoting long-term health after the diagnosis of cancer. J Clin Oncol 2005;23:5814-5830.

10. Bellizzi KM, Rowland JH, Jeffery DD, et al. Health behaviors of cancer survivors: examining opportunities for cancer control intervention. J Clin Oncol 2005;23:8884-8893

11. Eakin EG, Youlden DR, Baade PD, et al. Health behaviors of cancer survivors: data from an Australian population-based survey. Cancer Causes Control 2007;18:881-894.

12. Blanchard CM, Courneya KS, Stein $K$, et al. Cancer survivors' adherence to lifestyle behavior recommendations and associations with healthrelated quality of life: results from the American Cancer Society's SCS-II. J Clin Oncol 2008;26:2198-2204.

13. Mosher CE, Sloane R, Morey MC, et al. Associations between lifestyle factors and quality of life among older long-term breast, prostate, and colorectal cancer survivors. Cancer 2009;115:4001-4009.

14. World Cancer Research Fund/American Institute for Cancer Research. Food, Nutrition, Physical Activity, and the Prevention of Cancer: A
Global Perspective. Washington DC: AICR; 2007. Available at: http:// www.aicr.org/assets/docs/pdf/reports/Second_Expert_Report.pdf. Accessed April 1, 2017.

15. Hastert TA, Beresford SA, Patterson RE, et al. Adherence to WCRF/ AICR cancer prevention recommendations and risk of postmenopausal breast cancer. Cancer Epidemiol Biomarkers Prev 2013;22:1498-1508.

16. Catsburg C, Miller AB, Rohan TE. Adherence to cancer prevention guidelines and risk of breast cancer. Int J Cancer 2014;135:2444-2452.

17. Fanidi A, Ferrari P, Biessy C, et al. Adherence to the World Cancer Research Fund/American Institute for Cancer Research cancer prevention recommendations and breast cancer risk in the Cancer de Mama (CAMA) study. Public Health Nutr 2015;18:3337-3348.

18. Harris HR, Bergkvist L, Wolk A. Adherence to the World Cancer Research Fund/American Institute for Cancer Research recommendation and breast cancer risk. Int J Cancer 2016;138:2657-2664.

19. Nomura SJ, Inoue-Choi M, Lazovich D, et al. WCRF/AICR recommendation adherence and breast cancer incidence among postmenopausal women with and without non-modifiable risk factors. Int J Cancer 2016;138:2602-2615

20. Inoue-Choi $M$, Lazovich $D$, Prizment $A E$, et al. Adherence to the World Cancer Research Fund/American Institute for Cancer Research recommendations for cancer prevention is associated with better healthrelated quality of life among elderly female cancer survivors. J Clin Oncol 2013;31:1758-1766.

21. Inoue-Choi M, Robien $K$, Lazovich D. Adherence to the WCRF/AICR guidelines for cancer prevention is associated with lower mortality among older female cancer survivors. Cancer Epidemiol Biomarkers Prev 2013;22:792-802.

22. Zhang CX, Ho SC. Validity and reproducibility of a food frequency questionnaire among Chinese women in Guangdong province. Asia Pac J Clin Nutr 2009;18:240-250.

23. Yang YX, Wang GY, Pan XC. China Food Composition Table (2002 No. 1) (Chinese Edition). Beijing, China: Beijing University Medical Press; 2002.

24. Ho SC, Yu R, Chan S. Comparison of the modified Chinese Baecke Questionnaire with a 3-day activity diary in a Hong Kong Chinese population. Asia Pac J Public Health 2015;27:Np2358-2371.

25. Edge SB, Byrd DR, Compton CC, et al, eds. AJCC Cancer Staging Manual, 7th ed. New York, NY: Springer; 2010.

26. The Asia-Pacific Perspective: Redefining Obesity and Its Treatment. Available at: http://www.wpro.who.int/nutrition/documents/docs/ Redefiningobesity.pdf. Accessed April 1, 2017. 
Guideline Adherence and Quality of Life

27. Ainsworth BE, Haskell WL, Herrmann SD, et al. 2011 Compendium of Physical Activities: a second update of codes and MET values. Med Sci Sports Exerc 2011;43:1575-1581

28. Ledikwe JH, Blanck HM, Khan LK, et al. Dietary energy density determined by eight calculation methods in a nationally representative United States population. J Nutr 2005;135:273-278.

29. Chie WC, Chang KJ, Huang CS, et al. Quality of life of breast cancer patients in Taiwan: validation of the Taiwan Chinese version of the EORTC QLQ-C30 and EORTC QLQ-BR23. Psychooncology 2003;12:729-735.

30. Aaronson NK, Ahmedzai S, Bergman B, et al. The European Organization for Research and Treatment of Cancer QLQ-C30: a quality-of-life instrument for use in international clinical trials in oncology. J Natl Cancer Inst 1993;85:365-376.

31. Fayers PM, Aaronson NK, Bjordal K, et al. The EORTC QLQ-C30 scoring manual, 3rd ed. Brussels, Belgium: European Organisation for Research and Treatment of Cancer; 2001.

32. Maunsell E, Drolet M, Brisson J, et al. Dietary change after breast cancer extent, predictors, and relation with psychological distress. J Clin Oncol 2002;20:1017-1025.

33. Thomson CA, Flatt SW, Rock CL, et al. Increased fruit, vegetable and fiber intake and lower fat intake reported among women previously treated for invasive breast cancer. J Am Diet Assoc 2002;102:801-808.

34. Patterson RE, Neuhouser ML, Hedderson MM, et al. Changes in diet, physical activity, and supplement use among adults diagnosed with cancer. J Am Diet Assoc 2003;103:323-328.

35. Salminen E, Bishop M, Poussa T, et al. Dietary attitudes and changes as well as use of supplements and complementary therapies by Australian and Finnish women following the diagnosis of breast cancer. Eur J Clin Nutr 2004;58:137-144.

36. Wayne SJ, Lopez ST, Butler LM, et al. Changes in dietary intake after diagnosis of breast cancer. J Am Diet Assoc 2004;104:1561-1568.

37. Vance V, Campbell S, McCargar L, et al. Dietary changes and food intake in the first year after breast cancer treatment. Appl Physiol Nutr Metab 2014;39:707-714.

38. Song S, Hwang E, Moon HG, et al. Adherence to guidelines for cancer survivors and health-related quality of life among Korean breast cancer survivors. Nutrients 2015;7:10307-10319.
39. Shu XO, Zheng Y, Cai H, et al. Soy food intake and breast cancer survival. JAMA 2009;302:2437-2443.

40. Swann R, Perkins KA, Velentzis LS, et al. The DietCompLyf study: a prospective cohort study of breast cancer survival and phytoestrogen consumption. Maturitas 2013;75:232-240.

41. Xiao C, Miller AH, Felger J, et al. A prospective study of quality of life in breast cancer patients undergoing radiation therapy. Adv Radiat Oncol 2016;1:10-16.

42. Fang P, Tan KS, Troxel AB, et al. High body mass index is associated with worse quality of life in breast cancer patients receiving radiotherapy. Breast Cancer Res Treat 2013;141:125-133.

43. Fong DY, Ho JW, Hui BP, et al. Physical activity for cancer survivors: metaanalysis of randomised controlled trials. BMJ 2012;344:e70.

44. Courneya KS, Mackey JR, Bell GJ, et al. Randomized controlled trial of exercise training in postmenopausal breast cancer survivors: cardiopulmonary and quality of life outcomes. J Clin Oncol 2003;21:16601668.

45. Zeng $\mathrm{Y}$, Huang $M$, Cheng AS, et al. Meta-analysis of the effects of exercise intervention on quality of life in breast cancer survivors. Breast Cancer 2014;21:262-274.

46. Cramp F, Byron-Daniel J. Exercise for the management of cancer-related fatigue in adults. Cochrane Database Syst Rev 2012;11:CD006145.

47. Lee MK, Yun YH, Park HA, et al. A Web-based self-management exercise and diet intervention for breast cancer survivors: pilot randomized controlled trial. Int J Nurs Stud 2014;51:1557-1567.

48. Travier N, Fonseca-Nunes A, Javierre C, et al. Effect of a diet and physical activity intervention on body weight and nutritional patterns in overweight and obese breast cancer survivors. Med Oncol 2014;31:783.

49. Swisher AK, Abraham J, Bonner D, et al. Exercise and dietary advice intervention for survivors of triple-negative breast cancer: effects on body fat, physical function, quality of life, and adipokine profile. Support Care Cancer 2015;23:2995-3003.

50. Morey MC, Snyder DC, Sloane R, et al. Effects of home-based diet and exercise on functional outcomes among older, overweight longterm cancer survivors: RENEW: a randomized controlled trial. JAMA 2009;301:1883-1891.

See JNCCN.org for supplemental online content. 